\title{
Experimental Study and Model Development of Algal Based Industrial Wastewater Treatment
}

\author{
${ }^{1}$ Tsado, D. G., ${ }^{1}$ Adamu, M. ${ }^{2}$ Owolabi, O.E \\ ${ }^{1}$. Chemical Engineering Department, Federal Polytechnic, P.M.B. 55, Bida, Niger State, Nigeria. \\ 2. Mechanical Engineering Department, Federal Polytechnic, P.M.B. 55, Bida, Niger State, Nigeria.
}

\begin{abstract}
Industrial wastewater contain certain chemical nutrients especially compounds of nitrogen and phosphorus, and heavy metals which if discarded without treatment can lead to eutrophication and related environmental issues that affect the recycling processes of bio system. Currently, many efficient procedures exist for removing these nutrients but they usually present drawbacks in terms of cost-effectiveness, complexity of operation, waste generation (sludge) and/or high energy consumption. In order to overcome these problems, this research work focused on treating industrial wastewaters by using microalgae technology. Microalgae was cultivated on the industrial wastewater which provide not only water medium but also source of necessary nutrients suitable for algal cultivation, and thus treat the water by getting rid of these chemical nutrients. The algae selected for the study was spirulina sp. Various parameters like pH TDS, turbidity, Biological Oxygen Demand (BOD), Ammonium, Nitrogen, Phosphate and heavy metals were observed after the treatment. Percentage reduction rate of $35.6 \%$ (BOD), Algal productivity rate of $42 \%$ (average), and nitrogen reduction rate of $0.8 \%$ (average) were observed. Heavy metals involved such as iron, lead, cadmium and Zinc are found to decrease in the range of 60 to $80 \%$ per day and per growth of microalgae. Simulating the model for the effect of addition of $\mathrm{CO}_{2}$ into the pond, shows that at a flowrate of $10 \mathrm{~m}^{3} /$ hour, $62.5 \%$ increase of algal productivity is achieved and the maximum productivity is reached at $25 \mathrm{~m}^{3}$ /hour. The rate of productivity improvement gradually reduces as the gas flowrate increases. In the end of the studies, the simulation provides useful insights into optimal approaches for algal growth and thereby reducing costly experimental efforts. Therefore using microalgae is an environmentally safe alternative for treating wastewater as evident by algal growth rate, productivity and nutrient removal efficiency.
\end{abstract}

Key words: Microalgae, wastewater, heavy metals, carbon dioxide, chemical nutrients

\section{Introduction}

Algae are oxygen-evolving photosynthetic microorganisms and commonly grow in various aquatic environments, such as fresh and marine water, wastewater streams from a variety of wastewater sources (e.g., agricultural run-off, concentrated animal feed operations, and industrial and municipal wastewaters). Some species can grow on rocks, soils, plants, etc. as long as there are adequate amounts of $\mathrm{C}$ (organic or inorganic carbon), N (ammonium, nitrate, urea, yeast extract, etc.), and $\mathrm{P}$ as well as other essential trace elements presented. Wastewaters are unique in their chemical profile and physical properties as compared with fresh and marine waters. Wastewaters are unique in their chemical profile and physical properties as compared with fresh and marine waters.

Due to industrialization and urbanization pollution of surface water has become one of the most important environmental problems.

Recently, algae have become significant organisms for biological purification of wastewater since they are able to accumulate plant nutrients, heavy metals, pesticides, organic and inorganic toxic substances and radioactive matters in their cells/bodies (Kalesh and Nair, 2005). Biological wastewater treatment systems with micro algae have particularly gained importance in last 50 years and it is now widely accepted that algal wastewater treatment systems are as effective as conventional treatment systems. These specific features have made algal wastewaters treatment systems a significant low-cost alternative to complex expensive treatment systems particularly for purification of municipal wastewaters.

In addition, algae harvested from treatment ponds are widely used as nitrogen and phosphorus supplement for agricultural purpose and can be subjected to fermentation in order to obtain energy from methane. Algae are also able to accumulate highly toxic substances such as selenium, zinc and arsenic in their cells and/or bodies thus eliminating such substances from aquatic environments. Radiation is also an important type of pollution as some water contains naturally radioactive materials, and others become radioactive through contamination. Many algae can take up and accumulate many radioactive minerals in their cells even from greater concentrations in the water (Plume, 1999). Considering all these abilities of algae to purify the polluted waters of many types, it is worth to emphasize that algal technology in wastewater treatment systems are expected to get even more common in future years. 
It is well known that algae have an important role in self-purification of organic pollution in natural waters (Craggs et al., 1996). Moreover, many studies revealed that algae remove nutrients especially nitrogen and phosphorus, heavy metals, pesticides, organic and inorganic toxins, pathogens from surrounding water by accumulating and/or using them in their cells (Guha et al., 2001). Also, studies showed that algae may be used successfully for wastewater treatment as a result of their bioaccumulation abilities (Kwapi and Yu, 2001).

Growing algae requires the use of nutrients, $\mathrm{CO}_{2}$ and light. Supplying these growth requirements from manufactured sources will add to the operating cost and also reduces the lifecycle environmental benefits of the otherwise promising microalgal system. This is because as energy and raw material consumption, and GHG (greenhouse gas) emission will be high in the process of manufacturing these supplies. Therefore growing microalgae in nutrient-rich wastewater and waste air rich in $\mathrm{CO}_{2}$ will circumvent these problems (Clarens, et al., 2010).

Therefore this study seeks to remove nutrients and toxic metals to acceptable limits in industrial wastewater prior to discharge and or reuse, which is a major requirement in wastewater treatment. The use microalgae technology as means of this treatment is necessary for the fact that it is a natural means of treatment, and overcomes the major setbacks encountered in the present treatment methods. These setbacks include costeffectiveness, complexity of operation, waste generation (sludge) and/or high energy consumption. Another benefit is that algae biomass can be produced which can be channelled into biofuels production. In this work, a mathematical model has been developed and is used to evaluate the impact of the important operating parameters that affect open-pond performance with respect to algal productivity.

Selection of algae

\section{Materials And Methods}

For the purpose of this study microalgae sample used for the treatment of waste are collected from the stream River Landzun, in Bida, Niger State of Nigeria. The algae sample collected was identify to be "spirulina sp." and was transferred into a wide transparent rubber containing waste water.

\section{Selection of Wastewater}

Wastewater chosen was rice mill waste water which contains Nitrogen, Phosphorous and Heavy metals. The rice mill waste water was collected from Onyx Rice Mills, Bida, Niger State, Nigeria. This industry was chosen because rice is predominant in production in Bida and its environs and so, there abounds so many mills locally and sparingly, industrially.

\section{Microalgae Cultivation}

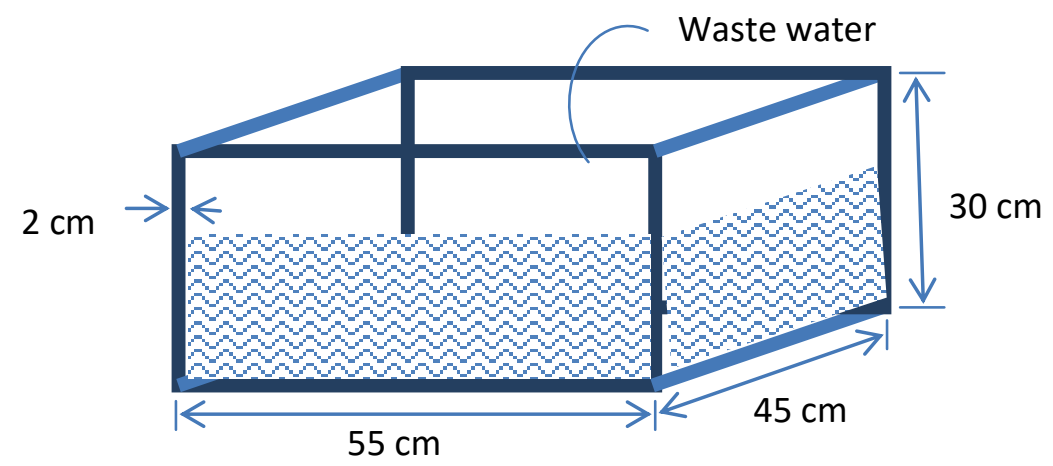

The industrial wastewater of about 10 litres was fed into open plastic tank of rectangular shape of $55 \mathrm{x}$ $45 \times 30 \mathrm{~cm}$ size, mechanically designed. This serves as an open pond in which the microalgae are cultivated. The tank/pond was operated at room temperature. Algae of initial dosage $20 \mathrm{~g}$ was fed to the tank/pond and allowed to grow with time. The plastic container for algae cultivation was outside to allow sun rays contact for photosynthesis.

\section{Experimental Procedures:}

\section{(i) Optimization of number of days}

The raw wastewater was initially taken for analysis in the areas of $\mathrm{pH}$ TDS, turbidity, Biological Oxygen Demand (BOD), Ammonium, Nitrogen, Phosphate and heavy metals. The 20g dosage of microalgae cultivated in the tank/pond was allowed to grow with time. At every two days interval samples of wastewater in the tank/pond were collected and analysis for the various parameters mentioned above for ten (10) days, while the microalgae increases in mass concentration. 


\section{Water Analysis}

The water being treated was analysed for various parameters which include $\mathrm{pH}$ TDS, turbidity, Biological Oxygen Demand (BOD), Ammonium, Nitrogen, Phosphate and heavy metals.

\section{(i) Determination of $\mathbf{p H}$}

$\mathrm{pH}$ is the term used to express the intensity of the acid or alkaline condition of a solution. The $\mathrm{pH}$ of the water was carried out using $\mathrm{pH}$-meter. The $\mathrm{pH}$ value can be defined as the logarithm to base 10, of the reciprocal of the concentration or $\mathrm{pH}$ value is equal to the logarithm of the hydrogen ion concentration with negative sign. This can be stated mathematically as

$\mathrm{pH}=\log _{10}\left(\mathrm{H}^{+}\right)=\log _{10}\left(\frac{1}{H+}\right)$

\section{(ii) Determination of Turbidity}

Turbidity is measured by simple comparison of the interference of light rays passing through a sample with that in standard samples. The procedure adopted for the measurement of turbidity was Photoelectric (nephelometric) procedure method.

\section{(iii) Determination of Total Solids}

The total solids (TS) are made up of dissolved solids (DS) and suspended solids (SS). TS = DS + SS Procedure:

A clean dish of suitable size was dried at $103-105^{\circ} \mathrm{C}$ in an oven until constant weight was achieved and it was cool to room temperature in a desiccators. The weight of the pipette was taken, after it was mixed thoroughly, 100-250ml (as found suitable) of water or effluent sample was accurately into a dish and evaporated to dryness on a steam bath. The outside of the dish was wiped and the residue was dried in an oven for about $11 \mathrm{hrs}$ at $103-105^{\circ} \mathrm{C}$. The dish was transferred quickly to a desiccators and cooled at room temperature and was weighed. The dish was then returned to the oven and was dried further for 10-20 minutes. Reweigh after cooling to room temperature. The procedure was repeated until the weight of the dish plus residues are constant to within $0.05 \mathrm{mg}$. The weight of the dish was subtracted from the initial weight to obtain the weight of the total solids.

\section{(iv) Determination of Biochemical Oxygen Demand (BOD)}

The BOD is a measure of the amount of oxygen required by micro-organisms to decompose the organic matter in a water sample under a specific set of conditions. Biochemical Oxygen Demand is also the amount of Oxygen expressed in milligram/litre, required for the decomposition of organic matter in a given water sample by aerobic bacterial action.

Usually samples for BOD are enriched with inorganic nutrients, buffered, seeded with bacteria and incubated in the dark for 5 days at $20^{\circ} \mathrm{C}$. The principle of this method is to measure the change over 5 days in dissolved oxygen concentration in a Stoppard bottle completely filled with the waste water or a sample of it.

\section{(v) Determination of Phosphate}

In a dilute phosphate solution, ammonium molybdate reacts in an acid medium to form a heteropoly acid, molybdoposphoric acid, which is reduced to the intensely coloured complex, molybdenum blue, by the combination of aminonaphtholsulphanic acid and sulphite reducing agents.

\section{(vi) Determination of Heavy Metals}

The heavy metals determined in this research include iron $(\mathrm{Fe})$, lead $(\mathrm{Pb})$, Cadmium $(\mathrm{Cd})$ and Zinc (Zn).

Metal in water samples are usually determined using Atomic Absorption Spectrophotometry. The sample was first aspirated into the flame or electrothermal device where it was vaporized and atomized. Rating of the proper wave length was then passed through the vapour containing the ground state atoms of the metal where absorption signed was directly proportional to the concentration of the analysed metal in the sample solution.

\section{Kinetic Model Development}

Kinetic model for algal nutrient utilization was developed with the assumption that the culture was a well-mixed homogeneous system.

The growth rate of algae is modelled by Equation (1):

$r_{A}=\mu_{A} X_{A}$

Where $\mu_{A}$ and $X_{A}$ are the specific growth rate and mass concentration of algae respectively. It should be noted that the specific growth rate of algae is affected by dissolved $\mathrm{CO}_{2}\left(\mathrm{CO}_{2 \mathrm{D}}\right)$ and total Nitrogen $\left(\mathrm{N}_{\mathrm{T}}\right)$, as well as light intensity, as stated in equation (2): 
$\mu_{A}=\kappa_{A}\left(\frac{C O_{2_{D}}}{K_{C}+C O_{2_{D}}}\right)\left(\frac{N_{T}}{K_{N A}+N_{T}}\right) f_{I}$

Where $K_{A}, K_{C}$ and $K_{N A}$ are constant. $f_{I}$, the light intensity factor, is modelled by the following equation (Steele, 1962):

$f_{I}=\frac{I_{a}}{I_{s}} \exp \left(1-\frac{I_{a}}{I_{s}}\right)$,

Where $I_{s}$ is the saturation light intensity, $I_{a}$ is the (spatial) average light intensity in the pond at a particular point in time.

Following Beer Lambert's law, $I_{a}$ can be estimated as follows:

$I_{a}=\frac{I_{o}}{A \cdot X_{a}}\left(1-e^{-A \cdot X_{a}}\right)$

Where $I_{o}$ is the surface light intensity, $\mu \mathrm{mol} \mathrm{m}{ }^{-3}$; and A is a coefficient with unit of $\mathrm{m}^{3} \mathrm{~kg}^{-1}$.

The parameters used for model simulation are given in Table 1.

Table 1: Numerical values of model parameters

\begin{tabular}{|l|l|l|}
\hline Parameter & Value & Reference \\
\hline$K_{A}$ & $0.9991 \mathrm{days}^{-1}$ & (Buhr and Millar, 1983) \\
\hline$K_{C}$ & $0.001 \mathrm{~mol} \mathrm{CO}_{2 \mathrm{D} \mathrm{m}}{ }^{-3}$ & (Buhr and Millar, 1983) \\
\hline$K_{N A}$ & $0.001 \mathrm{~mol} \mathrm{~N} \mathrm{~m}^{-3}$ & (Buhr and Millar, 1983) \\
\hline$I_{s}$ & $14.63 \mathrm{MJ} / \mathrm{m}^{2} /$ day & $\begin{array}{l}\text { Range of 8.36 to 20.9 MJ//m2 /day cited in } \\
\text { Beran and Kargi, (2005); an average taken } \\
\text { by this work. }\end{array}$ \\
\hline$I_{o}$ & $45 \mu \mathrm{mol} \mathrm{m}^{-2} \mathrm{~s}^{-1}$ & $\begin{array}{l}\text { Range of 40 - 50 } \mu \mathrm{mol} \mathrm{m} \mathrm{m}^{-2} \mathrm{~s}-1 \text { measured in } \\
\text { Lianet al. (2012) }\end{array}$ \\
\hline $\mathrm{A}$ & $14.7 \mathrm{~m}^{3} \mathrm{~kg}^{-1}$ & (Mart!'nezet al., 1997) \\
\hline
\end{tabular}

\section{Results And Discussions}

The results of this study are presented in the figures 1, 2 and 3, and Tables 1 and 2 below.

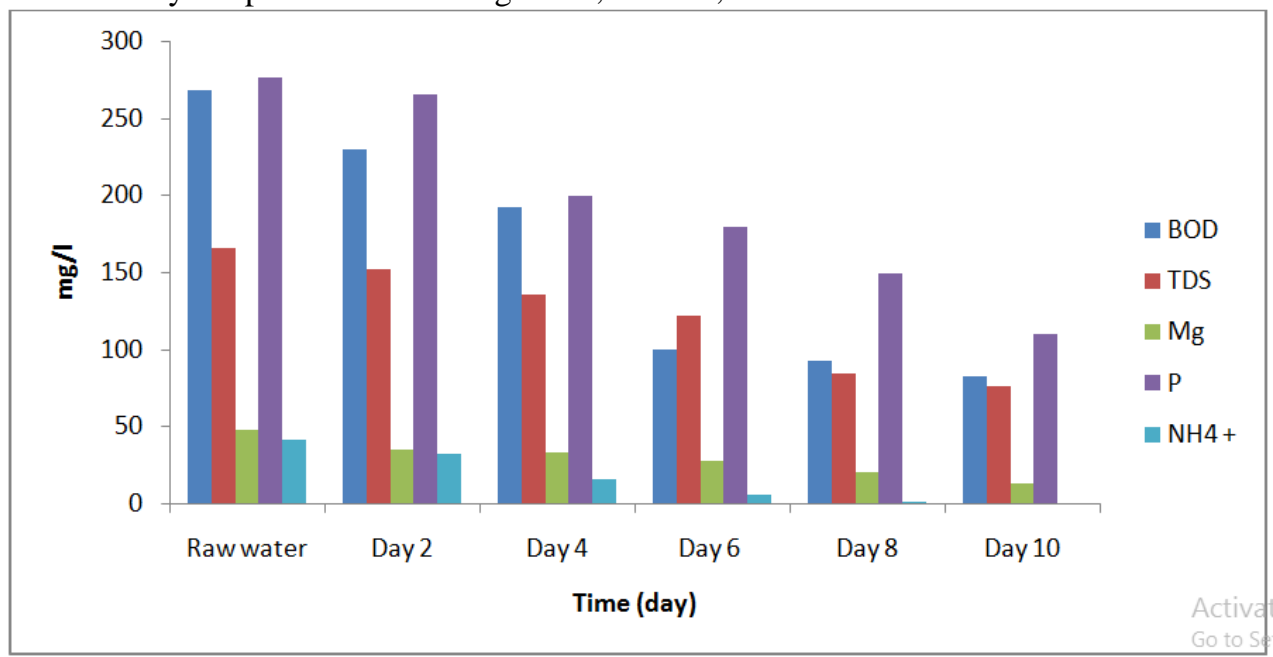

Figure 1: Laboratory Analysis on the Water Treatment duringAlgal Growth

Table 2: Laboratory Analysis on the Water Treatment during Algal Growth

\begin{tabular}{|l|l|l|l|l|l|l|l|}
\hline Parameter & $\begin{array}{l}\text { Raw } \\
\mathrm{H}_{2} \mathrm{O}\end{array}$ & Day 2 & Day 4 & Day 6 & Day 8 & Day 10 & $\begin{array}{l}\text { Max. WHO* } \\
\text { Standard }\end{array}$ \\
\hline $\begin{array}{l}\text { Algal Produced } \\
(\mathrm{g})\end{array}$ & 20 & 20.5 & 36.0 & 53.0 & 56.8 & 60.0 & \\
\hline pH & 6.30 & 6.80 & 6.80 & 6.98 & 7.20 & 7.35 & $6.5-8.5$ \\
\hline BOD (mg/l) & 268.05 & 230.10 & 193.06 & 100.01 & 92.00 & 82.00 & absent \\
\hline COD (mg/l) & 318.00 & 298.00 & 243.00 & 172.00 & 142.00 & 137.00 & absent \\
\hline TBT (NTU) & 9.00 & 3.50 & 1.50 & 1.00 & 0.50 & 0.51 & 5 \\
\hline
\end{tabular}




\begin{tabular}{|l|l|l|l|l|l|l|l|}
\hline $\mathrm{TDS}(\mathrm{mg} / \mathrm{l})$ & 166.00 & 152.00 & 136.00 & 122.00 & 83.72 & 76.05 & 500 \\
\hline $\mathrm{Mg}(\mathrm{mg} / \mathrm{l})$ & 48.00 & 35.00 & 33.00 & 27.00 & 20.00 & 13.00 & 150 \\
\hline $\mathrm{SO}_{4}{ }^{-}(\mathrm{mg} / \mathrm{l})$ & 300.00 & 182.00 & 176.50 & 154.40 & 134.00 & 124.00 & 250 \\
\hline $\mathrm{P}(\mathrm{mg} / \mathrm{l})$ & 276.3 & 265.00 & 200.00 & 180.000 & 150.00 & 110.00 & No limit listed \\
\hline $\mathrm{NH}_{4}{ }^{(\mathrm{mg} / \mathrm{l})}$ & 41.13 & 31.72 & 15.54 & 5.30 & 1.20 & 0.18 & 1.5 \\
\hline $\mathrm{Fe}(\mathrm{mg} / \mathrm{l})$ & 0.22 & 0.10 & 0.07 & 0.03 & 0.01 & N/A & 0.30 \\
\hline $\mathrm{Pb}(\mathrm{mg} / \mathrm{l})$ & 0.30 & 0.10 & 0.02 & 0.00 & N/A & N/A & 0.01 \\
\hline $\mathrm{Cd}(\mathrm{mg} / \mathrm{l})$ & 0.05 & 0.01 & N/A & N/A & N/A & N/A & 0.003 \\
\hline $\mathrm{Zn}(\mathrm{mg} / \mathrm{l})$ & 3.70 & 2.13 & 1.11 & 0.80 & 0.30 & 0.17 & 3.00 \\
\hline
\end{tabular}

* ---- Source: www.wikipedia.org

Key: N/A = Not Available

Industrial wastewater from rice mills industry was treated using microalgae, and algal biomass was concurrently produced upon its cultivation on the water. The results are presented in Table 2 and Figure 2. Considering the table, the $\mathrm{pH}$ of the water while undergoing treatment was maintained within the WHO limit, but it increases with days of cultivation of algae. This is in order because in algal cultures, $\mathrm{pH}$ usually increases due to the photosynthetic $\mathrm{CO}_{2}$ assimilation (Borowitzka, 1998; Chevalier et al., 2000). The BOD is quite high significantly which is from the source of the raw water. This an indication that the wastewater is highly polluted with organic matter and so the total amount of oxygen which is required to completely oxidize all of the organic matter in a sample to $\mathrm{CO}_{2}$ and water is thus high. It will take quite numbers of days or fresh algae be injected into the pond after harvesting the ones that are fully matured. The raw water is not high in turbidity and so the treated water turbidity all fall within the WHO limit of safe drinking water.

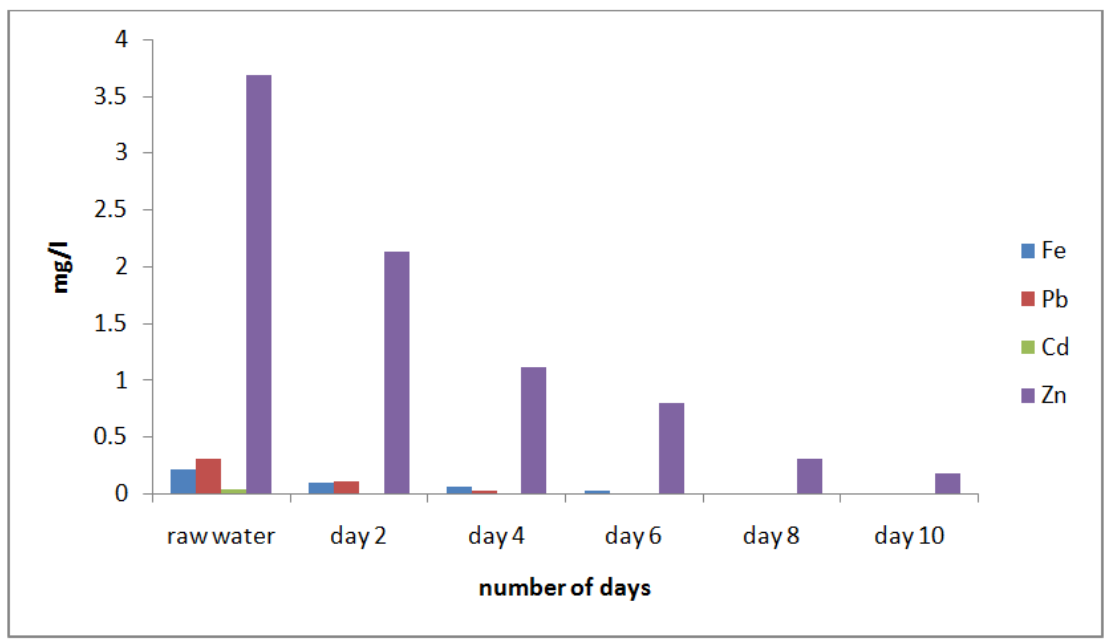

Figure 2: Heavy Metal Analysis on the Water at Various Days Interval as Algae Grows

Heavy metals involved such as iron, lead, cadmium and Zinc are found to decrease appreciatively with time as the microalgae grows, that is the heavy metals are being assimilated into algae in the range of 60 to $80 \%$ per day and per growth. Hence microalgae are known to feed on the impurities and heavy metals present in the waste water thereby treating it as grows.

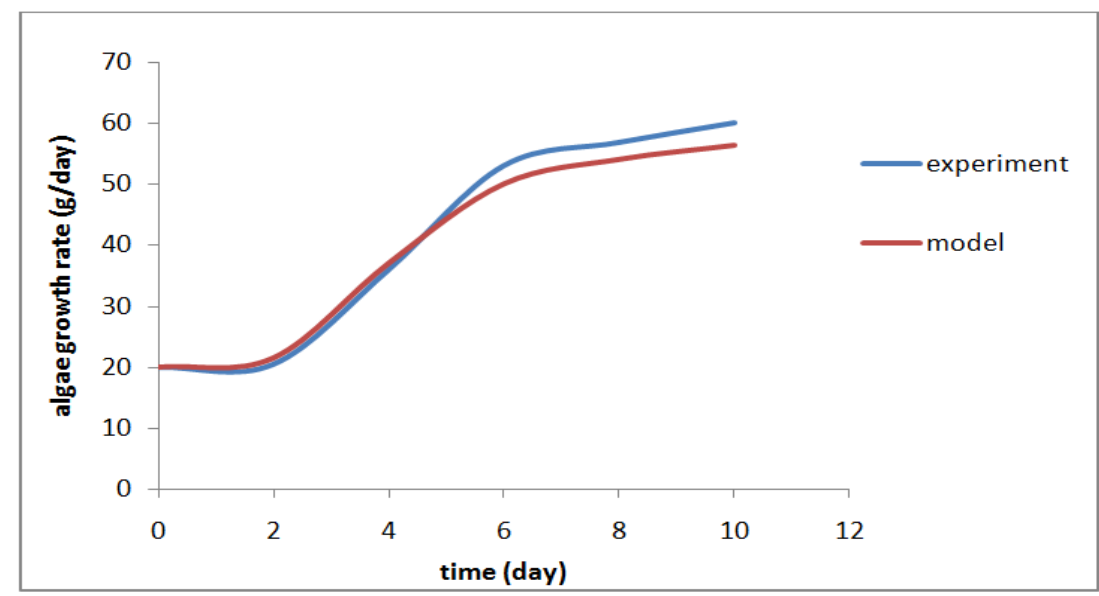

Figure 3: Comparison of Experimental and Modelled Algal Growth Rate 
Comparing the algal growth rate experimentally with the modelled one in Figure 3, it shows that the model simulation provides useful insights into optimal approaches for algal growth and thereby avoiding costly experimental efforts. There is a slight variation between the experimental and the modelled algal growth rate due to some limitations the model was subjected to. The limitations include inability of the model to account for the influence of toxic compounds (SOx and NOx) on the algal growth). The influence of the pond performance which includes pond depth was not taken into consideration. Lastly, the chemical reactions equilibriums involving $\mathrm{CO}_{2}, \mathrm{H}^{+}, \mathrm{OH}^{-}, \mathrm{NH}_{3}$, etc in the culture medium were oversimplified.

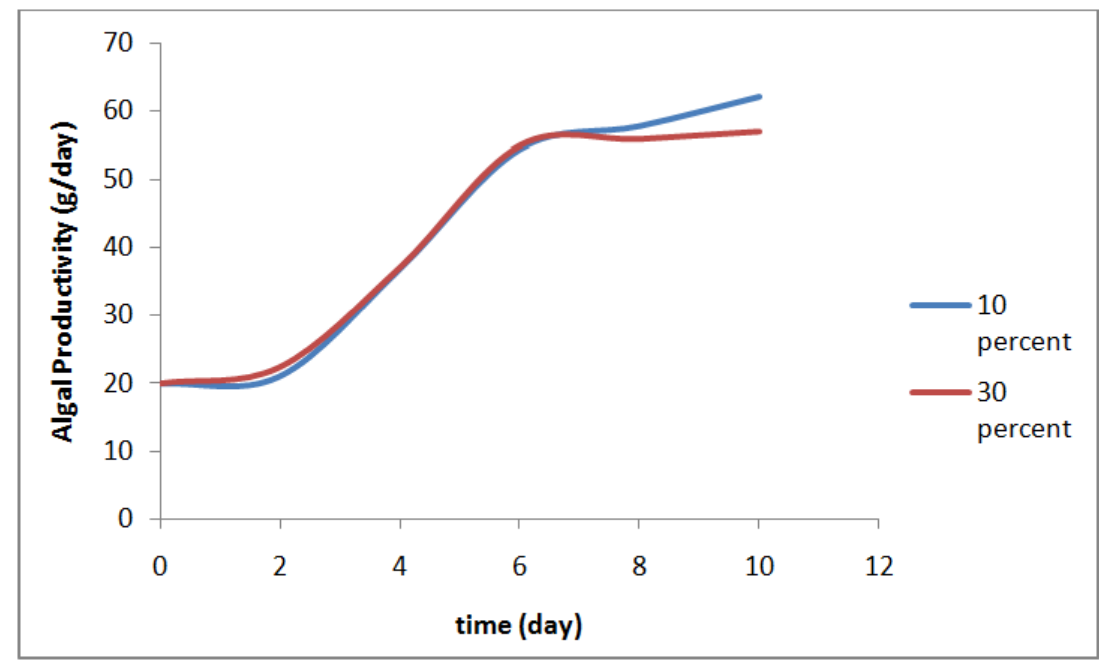

Figure 4: Effect of Algal Productivity on Addition of $\mathrm{CO}_{2}$

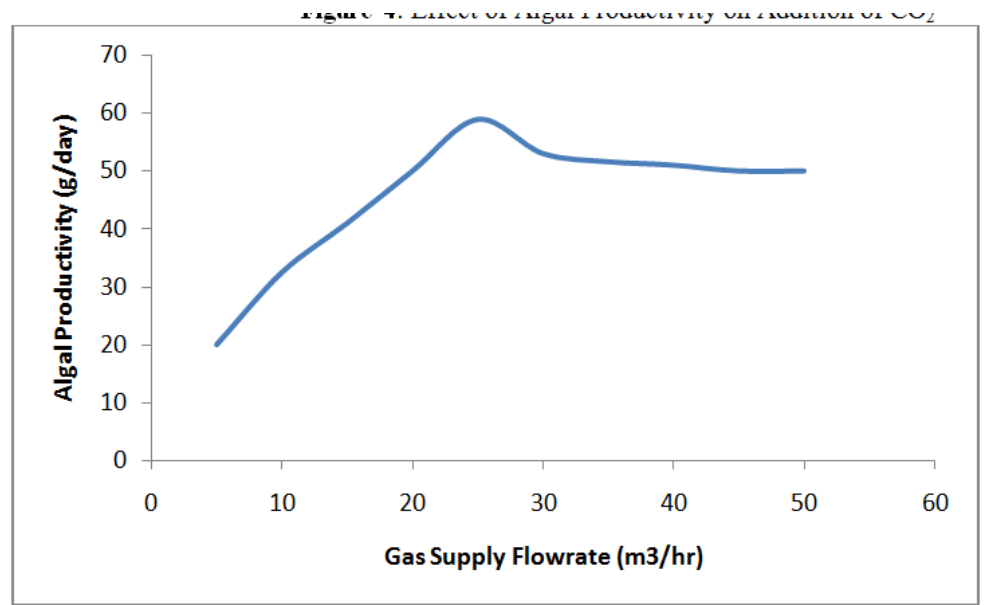

Figure 5: Effect of Algal Productivity on Increased $\mathrm{CO}_{2}$ Flowrates

Additional supply of $\mathrm{CO}_{2}$ into the pond leads to a more complex behaviour of the pond (Borowitzka, 1999). Figure 4 and Figure 5 show clearly the benefit of additional gas supply to the yield of algal biomass. At a flowrate of $10 \mathrm{~m}^{3}$ /hour, $62.5 \%$ increase of algal productivity is achieved and the maximum productivity is reached at $25 \mathrm{~m}^{3}$ /hour. The rate of productivity improvement gradually reduces as the gas flowrate increases.

\section{Conclusion}

Using experimental proceedings, industrial wastewater from rice mills industry was treated using microalgae, and algal biomass was concurrently produced upon its cultivation on the water. It can be concluded that microalgae can be used in wastewater treatment to reduce BOD, Nitrogen, Phosphorous, heavy metals. The kinetic model developed shows that the model simulation provides useful insights into optimal approaches for algal growth and thereby reducing costly experimental efforts, even though the model has some limitations. The model result also shows that continuous exposure $\mathrm{CO}_{2}$ gas in the pond severely inhibited the algal growth, however though; alga performance is enhanced with increased $\mathrm{CO}_{2}$ in the pond. The higher the volume of microalgae cultivated on the pond, the more efficient its wastewater treatment. 
It is recommended that

\section{Recommendation}

1. Other species of microalgae be identified for similar study, and the areas of this model did not account for should be included.

2. Microalgae should be applied in all developing and developed countries for wastewater treatment so as to protect the environmental pollution causing due to wastewater from industrial and domestic effluents, for its numerous advantages over the conventional methods which is not cost effective, complex and energy demanding to drive the technology.

\section{References}

[1] Beran, B.; Kargi, F.A (2005) Dynamic mathematical model for wastewater stabilization ponds. Ecological Modelling, 181 , $39-57$.

[2] Borowitzka, M.A. (1999) Commercial production of microalgae: ponds, tanks, tubes and fermenters. Journal of Biotechnology, 70, 313-321.

[3] Borowitzka, M.A. (1998) Limits to Growth, in Wastewater Treatment with Algae, Y.-S. Wong and N.F.Y. Tam, Editors. Springer Verlag. p. 203-226.

[4] Buhr, H. O.; Millar, S. B. A (1983) Dynamic-model of the high-rate algal bacterial wastewater -treatment pond. Water Res.17, 2937.

[5] Chevalier, P., Proulx, D., Lessard, P., Vincent, W.F., and de la Noüe, J. (2000) Nitrogen and Phosphorus Removal by High Latitude Mat-forming Cyanobacteria for Potential use in Tertiary Wastewater Treatment. J. Appl. Phycol. 12: p. 105- 112.

[6] Clarens, A. F.; Resurreccion, E. P.; White, M. A.; Colosi, L. M. (2010) Environmental Life Cycle Comparison of Algae to Other Bioenergy Feedstocks. Environ. Sci. Technol., 44, 1813-1819.

[7] Craggs, R. J., Adey, W. H., Jenson, K. R., John. M. S. St, Green, F. B. and Oswald, W. J. (1996).Relationship of Algae to Water Pollution and Waste Water Treatment Water.Journal of Science and Technology, (33)71, 91-98

[8] Guha, H., Jayachandran, K. and Mauresse, F. (2001) Kinetics of Chromium (VI) Reduction by a type strains Shewanella algae under different growth conditions. Journals of Environmental Pollution, (11)5, 910-918

[9] Kalesh N.S, Nair S.M (2005). The Accumulation Levels of Heavy Metals (Ni, Cr, Sr, \& Ag) in Marine Algae from Southwest Coast of İndia. Toxicological \& Environmental Chemistry (8)72. 135-146

[10] Kwapi, P., Yu, L. and (2001).Cadmium Removal from Aqueous Solutions by Marine Algal Biomass. Journal of Environmental Pollution, (09)22, 213-222

[11] Lian H., Venkat R. S. and Yinjie J. T. (2012) Experimental analysis and model-based optimization of microalgae growth in photobioreactors using flue gas. Biomass and Bioenergy 41,131-138

[12] Martı'nez M.E., Camacho F., Jime'nez J.M, and Espı'nola J.B. (1997) Influence of light intensity on the kinetic and yield parameters of Chlorella pyrenoidosamixotrophic growth. Process Biochem 32(2):93 - 8

[13] Plume, Y. T., (1999).Using Microalgae as Organic Composite in Water Pollution Control. J. Phycology.(5). 78-82

[14] Steele, J. H. (1962) Environmental control of photosynthesis in the sea. Limnology and Oceanography, 7, 137-150. www.wikipedia.org. Water Quality Standard 